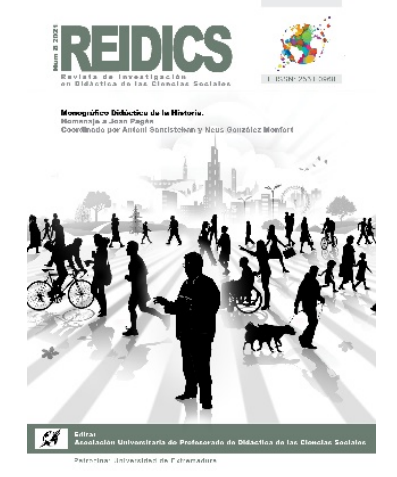

\title{
REIDICS
}

Revista de Investigación en

Núm. 8, 2021

Didáctica de las Ciencias

Recibido 19 de enero de 2021

Sociales

Aceptado 1 de marzo 2021

E-ISSN: 2531-0968

\section{Enseñar a pensar el futuro a través de la enseñanza y aprendizaje del tiempo histórico}

Teaching to think about the future by teaching and learning historical time

Carmen Escribano Muñoz

Universidad Internacional de la Rioja

Email: carmen.escribano@unir.net

ORCID: https://orcid.org/0000-0001-9372-5331

DOI: https://doi.org/10.17398/2531-0968.08.38

\section{Resumen}

El estudio que aquí se presenta tiene por objeto indagar en las representaciones que han construido futuros docentes de Educación Primaria, en referencia a la enseñanza y aprendizaje del tiempo histórico. Para ello, se analiza una actividad planteada en la asignatura de Didáctica de las Ciencias Sociales, en la que los y las estudiantes de profesor debían diseñar una propuesta didáctica para enseñar a enseñar el tiempo histórico. Los resultados muestran que se percibe un cambio en las metodologías y estrategias didácticas que aplican. Sin embargo, en la mayoría de propuestas prevalece una enseñanza del tiempo histórico que se relaciona fundamentalmente con la cronología y el estudio del pasado. Con un porcentaje menor se encontraron propuestas que contemplaban la relación entre pasado-presente, y fueron muy pocas las propuestas en las que se incorporaban estrategias para que el alumnado aprendiera a pensar el futuro. Los resultados evidencian lo que ya nos indican las investigaciones revisadas, la enseñanza de la historia permanece anclada en prácticas didácticas con escasa incidencia en el desarrollo de la conciencia histórica para ubicar al alumnado en el mundo en el que vive, adquirir conciencia de responsabilidad frente a los problemas de su presente y pensar con prospectiva de futuro.

Palabras clave: tiempo histórico; conciencia histórica; futuro; formación inicial; educación primaria.

\section{Abstract}

The present study aims to investigate the representations that have built future primary education teachers, in reference to teaching and learning of historical time. To do this, we analyze an activity proposed in the course of Social Sciences Didactics, in which students of teachers had to design a didactic proposal to teach historical time. The results show that there is a change in the methodologies and didactic strategies that they apply. However, in most of the proposals, a teaching of historical time predominates, which is fundamentally related to 
the chronology and study of the past. With a smaller percentage, proposals were found that contemplate the relationship between past and present, and very few proposals incorporated strategies for students to learn to think about the future. The results show what the revised research has already indicated to us, the teaching of history remains anchored in teaching practices with little impact on the development of historical consciousness to place the student in the world in which he lives, to become aware of responsibility for the problems of his present and to think forward.

Keywords: historical time; historical awareness; future; initial training; primary education.

\section{Introducción}

Desde pequeños ya nos introducen en el fascinante mundo de la historia, y su aprendizaje nos proporciona una serie de conocimientos que nos permiten identificar y recordar los principales acontecimientos del pasado, así como los grandes avances y descubrimientos de la humanidad. Desde esta concepción, la historia, como ciencia que reconstruye e interpreta el pasado, nos informa sobre lo que pasó y sobre las decisiones que tomaron otras personas por nosotros, decisiones que, en gran medida, han marcado nuestro presente (Pagès, 1988, 1999a, 1999b).

Partiendo de los retos educativos que nos plantea el presente, el alumnado de nuestras escuelas no se debe educar únicamente para responder a las preguntas del pasado, sino para responder a las cuestiones que le planteará el futuro (Santisteban y Anguera, 2014).

En este sentido, la enseñanza de la historia debe servir a nuestro alumnado para entender el mundo en el que vive, comprender mejor el origen del presente y poder responder a las cuestiones que le plantea el futuro. Sin embargo, la historia que se ha enseñado en las aulas, nunca ha pretendido situarnos en el presente y mucho menos pensar en el futuro, más bien ha ido reproduciendo e interpretando los hechos históricos para construir una imagen del pasado que genere conciencia sobre nuestros orígenes e identidad, sin tener en cuenta que lo que realmente nos interesa es conocer el mundo en el que vivimos y los retos a los que nos enfrentamos (Pagès, 1999b).

Desde esta perspectiva, el docente debe poder promover estrategias didácticas adecuadas para que el alumnado establezca relaciones entre el pasado, el presente y el futuro, problematizando el contenido histórico a partir del análisis de una situación o problema actual, buscar sus orígenes y pensar críticamente en posibles soluciones (Pagès, 2009; Jiménez Martínez y Felices de la Fuente, 2018). De manera que comprendan que el pasado nos puede ayudar a pensar y construir futuros deseables y posibles desde el presente (Santisteban, 2005). Como docentes debemos reflexionar sobre las finalidades de la enseñanza de la historia, máxime si contemplamos que el presente es la consecuencia del pasado y el pasado está presente en nuestras representaciones del futuro.

Pero la realidad es que en la práctica docente actual sigue apareciendo reflejada una visión reduccionista de la historia y del tiempo histórico que repercute en la concepción que los futuros docentes asumen sobre su enseñanza y aprendizaje (Escribano, 2019). En este sentido, nos cuestionamos si en la actualidad, el alumnado de primaria y secundaria adquieren las 
competencias necesarias para leer el presente, desde el análisis y explicación del hecho histórico del pasado, y pensar en la construcción de su futuro.

Los resultados de diversas investigaciones revisadas nos indican que sí ha habido un cambio y se ha tomado cierta conciencia de la necesidad de repensar una enseñanza de la historia que forme el pensamiento crítico y que relacione el pasado con el presente, pero, en menor medida, pasado y presente se han relacionado con el futuro (Anguera, 2012; Pagès, 1997, 1999a,1999b, 2009, 2019; Santisteban, 2005; Escribano, 2019).

Desde esta perspectiva, la percepción del tiempo histórico es una de las claves para abordar el análisis y la comprensión de la historia. Pensar la historia permite que los que serán los futuros ciudadanos y ciudadanas del mundo, construyan progresivamente su personalidad y valoren la actividad constante en el devenir del ser humano en sociedad. Y aunque la tarea de enseñar el tiempo histórico puede ser compleja, Seixas y Morton (2013) señalan que se puede lograr si se parte de la concepción de que el conocimiento histórico no es algo acabado, sino que está vivo y es conocimiento necesario para el futuro de la sociedad.

En este sentido, las aportaciones de la investigación en la didáctica de la historia, permiten que nos detengamos sobre determinados aspectos de la estructura interna del tiempo histórico y de su complejidad. Principios y fundamentos que deben contemplarse en la formación inicial del profesorado para enseñar a pensar en el futuro a través de la enseñanza y aprendizaje del tiempo histórico.

\section{Conceptualización sobre el tiempo histórico}

En demasiadas ocasiones, nos encontramos que la enseñanza y aprendizaje de la historia y del tiempo histórico se relacionan únicamente con la medida del tiempo, es decir, con el estudio de las horas del reloj, del calendario o la cronología histórica. Sin embargo, el tiempo histórico no debe concebirse como algo único y lineal, sino que debe basarse en una concepción multidimensional, versátil y de naturaleza holística que solo puede ser entendida como un sistema o entramado de conexiones que se establecen entre presente, pasado y futuro, y las asociaciones que se dan a través de ciertos elementos temporales y operadores cognitivos que, como apunta Santisteban (2007) van aumentando a medida que incrementamos nuestro bagaje y experiencias de un tiempo vivido.

Hablamos pues de una renovada concepción del tiempo histórico que se construye desde la multiplicidad que caracteriza el tiempo, donde se contempla el pasado, el presente y el futuro como convecciones temporales que se deben adquirir para el desarrollo de la conciencia histórica, entendida como el pertenecer a un tiempo histórico determinado, ser responsable del presente y mejorar las posibilidades del futuro.

Partiendo de estas ideas y de las diferentes propuestas realizadas por Pagès (1997), Pagès y Santisteban (1999) y Santisteban (2005) se configuró una estructura conceptual del tiempo histórico que fue revisada por Escribano (2019) (Figura 1), la cual nos permite comprender cuáles son los elementos que se deben tener en cuenta en el proceso de enseñanza y aprendizaje de la historia y, a su vez, nos ayudan a proporcionar al profesorado en formación, un marco referencial que les pueda servir de base para su enseñanza en las escuelas de primaria y secundaria. 


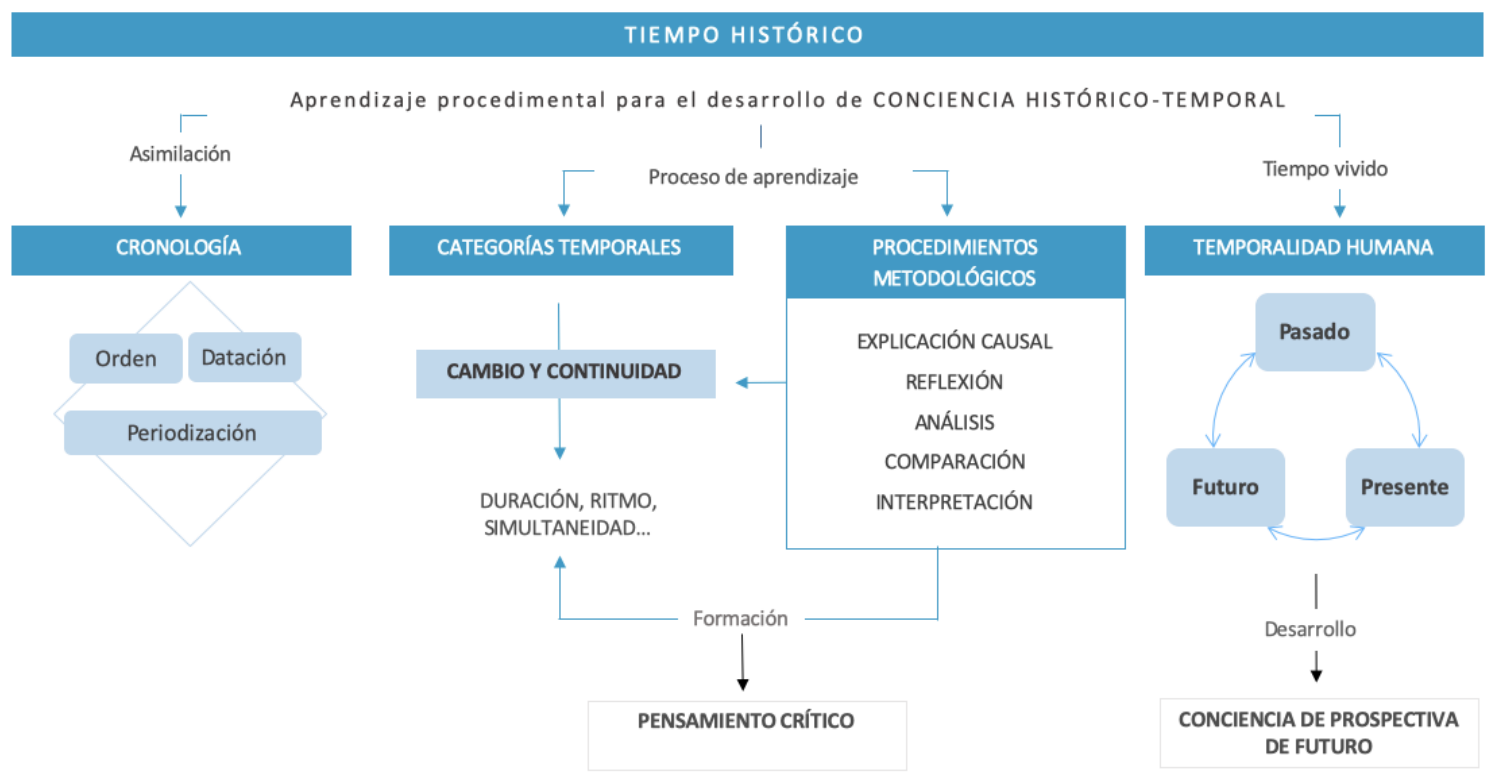

Figura 1. Estructura conceptual del tiempo histórico

Fuente: Escribano (2019)

\subsection{El tiempo histórico se contempla como un aprendizaje procedimental para el desarrollo de la conciencia histórica}

Tener conciencia de nuestra temporalidad es uno de los puntos de partida de la mayor parte de nuestras acciones. En el ámbito del conocimiento histórico, el dominio de la temporalidad nos permite ordenar los hechos del pasado y comprender nuestro presente, encontrando así un sentido del tiempo que se dirige a pensar en posibles futuros (Pagès y Santisteban, 2010).

Pensar la historia posibilita el conocer otras perspectivas y visiones pasadas que permiten a las personas ubicarse en el mundo en el que viven, adquirir conciencia de responsabilidad frente a los problemas sociales de su presente y desarrollar la capacidad crítica de pensar con prospectiva de futuro para tomar decisiones a favor de la intervención social (Escribano, 2019). En este sentido, como señala Anguera (2014) el desarrollo de la conciencia histórica incide en la relación presente-pasado-futuro, ya que la educación para el futuro necesita de la reflexión sobre el pasado.

\subsection{La adquisición y asimilación de la cronología como categoría temporal necesaria para la enseñanza del tiempo histórico}

La cronología ayuda a establecer el antes y el después de las cosas, de los hechos históricos, es una medida básica del tiempo y constituye el elemento inicial necesario para la comprensión del tiempo histórico.

El aprendizaje y ubicación de fechas va proporcionando un marco temporal. Sin embargo, este es de carácter fragmentario y no garantiza la comprensión de los acontecimientos históricos, si no se trabajan otras categorías temporales como son el cambio, la continuidad y la causalidad. 
En este sentido, el conocimiento histórico no se basa únicamente en saber cuándo ocurrió un hecho determinado o qué paso en una fecha concreta, sino que se caracteriza por conocer por qué ocurrió y cuales han sido sus consecuencias en el presente (Pagès, 1989, 1999a).

\subsection{El análisis de los cambios y las continuidades de la historia son el eje central para comprender el tiempo histórico}

El concepto de cambio es inseparable del de continuidad, son elementos que forman parte del devenir humano. El análisis de estos cambios y permanencias hace posible la construcción y comprensión del pasado (Pagès, 1999a; Santisteban, 2007). Pensar la historia nos ayuda a reflexionar sobre la ruptura de ciertos patrones sociales y culturales que se han ido produciendo en sociedades anteriores, y sobre aquellos aspectos que continúan formando parte de nuestro presente.

\subsection{La duración, los ritmos y la simultaneidad nos permiten comprender la noción de tiempo histórico en su totalidad}

Estas categorías temporales son una construcción mental progresiva que vamos aprehendiendo en base a nuestras experiencias y observación de los cambios y continuidades que se producen en el pasado.

Estos cambios y permanencias son los que han creado nuestro tiempo social presente, que es diferente en cada sociedad y en cada cultura y que posee diferentes ritmos evolutivos y duraciones. Por tanto, es necesario considerar la existencia de una pluralidad de tiempos como reflejo de los cambios en los diferentes fenómenos que coexisten en cada sociedad (Pagès, 1997).

\subsection{La comparación, el análisis causal y la interpretación de hechos y procesos históricos son procedimientos metodológicos necesarios para la explicación histórica}

Pagès (1997) considera que el aprendizaje de la historia debe consistir en poder explicar la relación de las sociedades con sus cambios en el tiempo. Analizar los motivos, las situaciones y los hechos vinculados al cambio y a la continuidad, así como clarificar las causas y las consecuencias que lo han promovido. Asimismo, establecer comparaciones sobre hechos históricos similares en distintas épocas ayuda a definir con claridad los tiempos pasados y su vínculo con el tiempo presente.

Esto implica que el docente promueva en el aula situaciones problema, plantee preguntas y actividades de carácter inductivo para que el alumnado contraste, elabore hipótesis, confronte la información, resuelva problemas, etc. De esta manera, tendrán capacidad de abordar su estudio con autonomía y construir su propia representación del pasado de una forma crítica (Pagès, 2009; Santisteban, González y Pagès, 2010). 


\subsection{El tiempo histórico contribuye al desarrollo de habilidades para formar el pensamiento crítico}

El pensamiento crítico impulsa el desarrollo de la literacidad crítica, entendida como un conjunto de habilidades que se van aprendiendo y que acaban convirtiéndose en una manera de pensar y de comunicarse con los demás de una forma crítica y responsable. Se trata pues de abordar cualquier tipo de información, texto o relato, sobre el pasado, el presente o el futuro y enseñar al alumnado a analizar la naturaleza de la información, valorar su veracidad y evaluar la fiabilidad de las fuentes, para que puedan formar un juicio crítico y tomar decisiones para intervenir socialmente (Tosar, 2018; Castellvi, Tosar y Andreu, 2020).

\subsection{Nuestra temporalidad se construye a través de la interrelación entre el pasado, el presente y el futuro}

Es esencial establecer relaciones entre las tres categorías de la temporalidad humana, entendiendo el pasado como la memoria y el recuerdo, el presente como el instante y la historia próxima, y el futuro como prospectiva (Santisteban, 2007). En este sentido, hacerles entender al alumnado está relación dialéctica entre pasado, presente y futuro es fundamental para comprender que el conocimiento del pasado permite vivir una realidad que puede llegar a ser mucho más significativa para el alumnado, ya que contribuye a formar su propia identidad personal y social, y responde a quiénes somos y qué queremos ser en el futuro (Escribano, 2019).

\section{El tiempo histórico y su relación con el futuro}

De entre las finalidades de la enseñanza de las Ciencias Sociales y, en concreto, la enseñanza de la historia, en el currículo español se formula la necesidad de preparar al alumnado para su futuro papel como ciudadano. En este sentido, la enseñanza de la historia debe poder ofrecer una serie de contenidos que permita a los estudiantes entender el mundo actual y sus conexiones con el pasado. Para ello, el docente debe lograr que el alumnado conecte con la realidad actual, entienda la sociedad en la que vive y adquiera las competencias necesarias para ejercer, en el futuro, una ciudadanía participativa y comprometida que le permita intervenir en los problemas sociales (Pagès, 2007).

En el ámbito de la didáctica de la historia, contamos con diversos estudios y propuestas que reivindican la enseñanza del pasado para la comprensión del presente (Blanco, 2007; Carretero y Montanero, 2008; Maestro, 2001; Pons, 2017; Torres, 2001) pero ¿qué pasa con la enseñanza del futuro?, ¿puede la enseñanza del pasado enseñar a pensar el futuro? y ¿a construirlo? A partir de los estudios iniciados en el año 1988 por el profesor Joan Pagès se redefine el concepto de tiempo histórico y se plantea, desde su enseñanza y aprendizaje, las relaciones entre el pasado, el presente y el papel que el futuro ejerce para la toma de conciencia del alumnado sobre la construcción de su propio tiempo y ubicarse ante el futuro. Todo ello, ligado a la necesidad social de educar en y para una ciudadanía democrática, el aprendizaje del tiempo histórico posibilita el desarrollo de competencias que permiten a nuestros estudiantes no solo pensar en el futuro si no también 
prepararlos para intervenir en su construcción. Hablamos pues de la relación entre la enseñanza de la historia y la educación para la ciudadanía (Anguera, 2012; Pagès, 1988, 1997, 2004, 2009, 2011, 2019; Pagès y Santisteban, 1999, 2008, 2010; Santisteban, 2005,2007; Henríquez, 2008; Llusà, 2015; Escribano, 2019).

Estos estudios se centran en la formación del pensamiento histórico y social del alumnado y el desarrollo de la conciencia histórica, donde se plantean alternativas focalizadas en el análisis del cambio, la continuidad, la causalidad histórica, la contemporaneidad y la enseñanza del futuro. Se trata pues de enlazar el conocimiento histórico a los problemas del mundo actual para así poder responder a las cuestiones que plantea el futuro, desde una perspectiva crítica. En este sentido, adquirir la competencia crítica supone ser capaz de ponerse en el lugar del otro, aceptar las diferencias, ser tolerante y respetar los valores, las creencias, las culturas y la historia personal y colectiva de los otros (Escribano, 2019).

\subsection{La enseñanza del tiempo histórico para aprender a pensar el futuro}

En referencia a las investigaciones llevadas a cabo para la enseñanza del tiempo histórico, recuperamos el estudio de Pagès (1999a): El tiempo histórico: ¿qué sabemos sobre su enseñanza y su aprendizaje?, donde se realiza un análisis y valoración de los resultados de investigaciones que se desarrollaron durante la década de los 90, concluyendo que los docentes, ya sea por las exigencias del currículo o por sus propias representaciones, en torno a la enseñanza de la historia y su concepción sobre el tiempo histórico, acaban enseñando conocimientos conceptuales, ya que son las pruebas evaluativas las que determinan el rendimiento académico del alumno, y es este tipo de conocimiento el que predomina en los currículos por encima del resto.

Pagès y Santisteban (1999) presentan una nueva propuesta de estructura del tiempo histórico en las que se contempla su enseñanza como construcción del futuro. En este marco conceptual se referencian aspectos de su enseñanza que posibilitan que el alumnado reflexione sobre los futuros posibles, probables o deseables y atiende a la formación del pensamiento críticocreativo, la responsabilidad ciudadana y la intervención social.

El estudio realizado por Santisteban (2005) muestra una estructura conceptual del tiempo histórico que plantea la importancia de comprender nuestra temporalidad, así como poder establecer relaciones entre pasado, presente y la construcción del futuro. El autor analiza las representaciones de los futuros docentes de primaria así como sus propuestas didácticas sobre la enseñanza del tiempo histórico. Los resultados nos indican que las conexiones entre el pasado, el presente y el futuro son prácticamente inexistentes, ya que la historia que se enseña en la mayoría de aulas viene determinada por los contenidos de los libros de texto y no es útil para que el alumnado relacione pasado, presente y mucho menos que haga proyecciones de futuro.

Por otro lado, el autor señala que la percepción y representación que realiza el docente sobre el tiempo histórico es un reflejo de sus competencias y capacidades prácticas para abordar la enseñanza de la historia en la práctica real. En este sentido, las experiencias del futuro docente, en su proceso de formación, se han tomado como patrón didáctico que incorpora a sus prácticas educativas, y este patrón sigue relacionando el tiempo histórico únicamente con la cronología y el pasado. 
En un estudio posterior de Escribano (2019) se analizaron diferentes propuestas didácticas diseñadas por estudiantes del Máster en Formación del Profesorado de Secundaria, en la especialidad de Geografía e Historia, con la finalidad de conocer cuáles eran los elementos temporales que hacían servir los futuros docentes en sus propuestas didácticas, y si contemplaban la relación entre pasado, presente y futuro.

Durante el análisis de los resultados se identificaron tres tipos de perfil docente: "reproductor", "guía" y "crítico", las cuales se enmarcaron a partir de las categorías que emergieron durante el análisis de la información que aparecía en las propuestas didácticas: "estudio del pasado" -perfil docente reproductor- , "conexión pasado-presente"- perfil docente guía- , "relación pasado-presente-futuro"-perfil docente crítico (Figura 3).

En relación con la enseñanza del tiempo histórico, prácticamente el 75\% de los docentes en formación proponían ejercicios y actividades relacionadas con la periodización de diferentes etapas históricas y la creación de líneas del tiempo. Por tanto, se identificaron en el perfil de docente "reproductor", ya que para la enseñanza del tiempo histórico utilizaban elementos temporales, mayoritariamente de carácter cronológico, que respondían más bien al ¿qué y cuándo ocurrió el hecho histórico? y no al ¿por qué ocurrió? ¿cuáles fueron sus causas? y ¿qué repercusiones se evidencian en el presente? Es decir, se centraban únicamente en el estudio del pasado.

En cuanto a la relación entre pasado, presente y futuro, no se encontraron propuestas didácticas en la que se plantearan estrategias para que el alumnado pudiera relacionar problemas del presente con problemas similares ocurridos en el pasado, y tampoco ofrecían herramientas para que el alumnado pudiera reflexionar sobre las posibles expectativas del futuro.

En líneas generales, los resultados de los estudios revisados nos indican que abordar el estudio del futuro no acaba de ser objeto de enseñanza y aprendizaje en la historia, y no se contempla como una categoría temporal a tener en cuenta para la enseñanza del tiempo histórico. Desde este punto de vista, como docentes, debemos reflexionar sobre las finalidades de la enseñanza de la historia y ayudar a nuestros alumnos a que conciban que el presente es el resultado del pasado, y el conocimiento histórico les va a permitir conocer las claves de la sociedad de la que forman parte, para así poder construir un futuro mejor que les evite reincidir en los errores que se pudieron cometer en el pasado, pues en definitiva, las personas somos quienes cambiamos el rumbo de las sociedades, somos quienes creamos la historia.

La formación de una ciudadanía democrática y el desarrollo de la conciencia histórica, definen una nueva forma de concebir la enseñanza de la historia, cuyo propósito es encaminar a la humanidad hacia una sociedad mejor. Sin embargo, parece que estas ideas permanecen en una «utopía educativa» entre los ideales, la realización práctica y la aplicación realista (Escribano, 2019).

\section{Metodología y objetivos}

Esta investigación se plantea desde una perspectiva cualitativa de carácter descriptivo e interpretativo (Sandín, 2003) donde se analizan las propuestas didácticas realizadas por 22 
estudiantes que están cursando la asignatura de didáctica de las Ciencias Sociales en la titulación de Grado en Maestro en Educación Primaria, por la Universidad Internacional de la Rioja.

Nuestro estudio trata de analizar la dinámica de reflexión que manifiestan los futuros docentes durante la elaboración de las actividades didácticas planteadas para la enseñanza del tiempo histórico, y descubrir aquellos principios y posicionamientos que subyacen en los contenidos y actividades que programan.

Para ello, la primera tarea que realizamos fue tomar como base la estructura del modelo conceptual del tiempo histórico (Figura 1) y presentarla a los y las estudiantes en una clase magistral días previos a la realización de la actividad, en la que debían presentar su propuesta de actividades para la enseñanza del tiempo histórico.

\section{Análisis y discusión de los resultados}

Se clasificó la información obtenida de las propuestas didácticas utilizando las categorías previamente construidas por Escribano (2019) (Figura 2), las cuales clasifican la información analizada en tres perfiles docentes: Reproductor, humanista y crítico.
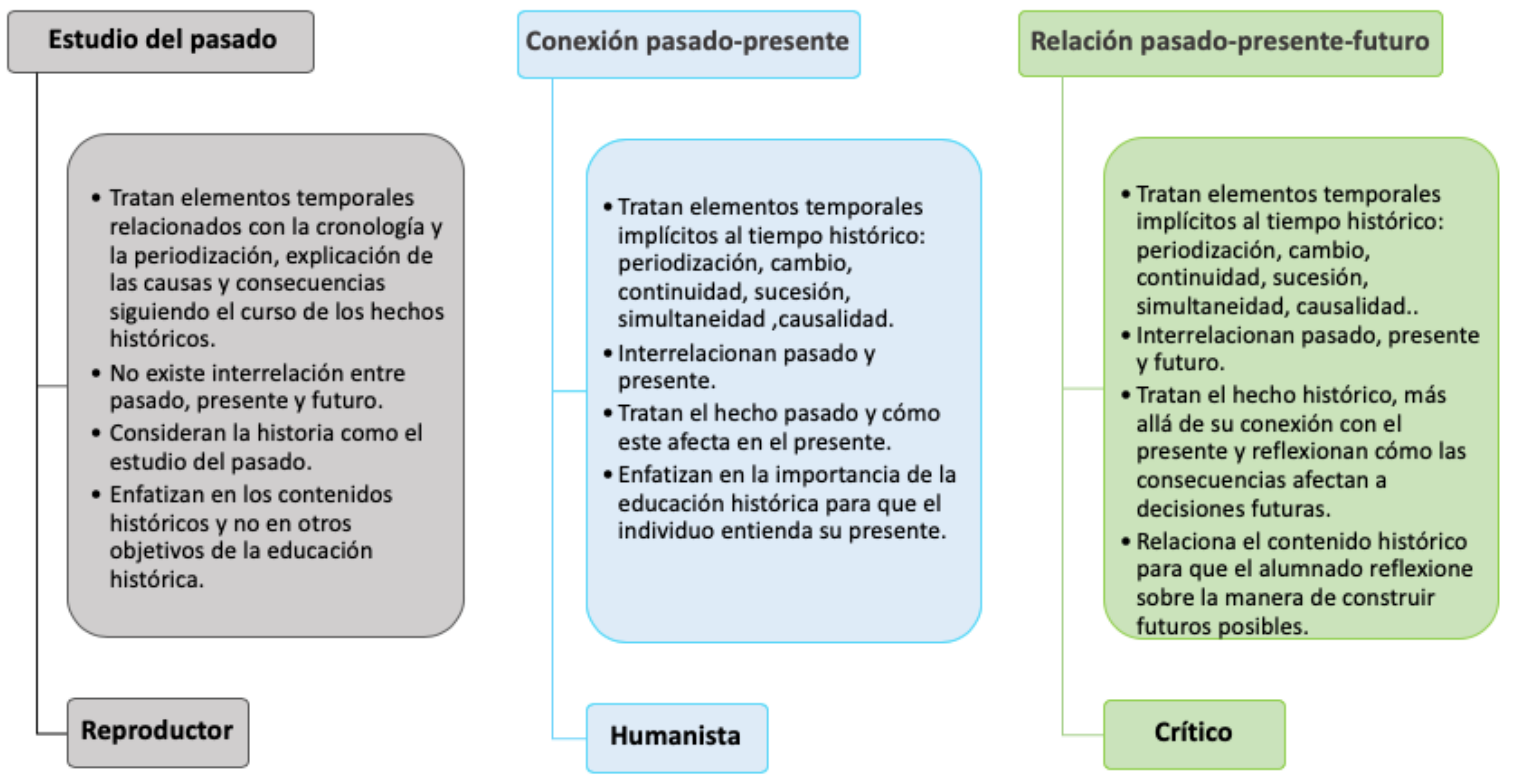

Figura 2. Categorías para el análisis y clasificación de la información de las propuestas didácticas.

Fuente: Escribano (2019)

En referencia al perfil docente "reproductor", los y las estudiantes abordan los contenidos históricos relacionándolos únicamente con el pasado, tratan elementos temporales principalmente de carácter cronológico, y no desarrollan estrategias didácticas para que su alumnado analice y construya el hecho histórico desde el presente, sino que siguen el curso de los hechos históricos. Este perfil se centra más en reproducir el conocimiento histórico que en promover habilidades del pensamiento como argumentar las causas y consecuencias del hecho histórico estudiado, de manera que el alumnado de sentido al conocimiento histórico en su contexto actual. 
El perfil docente "humanista" se caracteriza por poner énfasis en el desarrollo de un sujeto pensante, reflexivo y crítico frente a la realidad. En sus propuestas didácticas utilizan elementos temporales de carácter más cualitativo que actúan como organizadores cognitivos. La finalidad es que el alumnado establezca conexiones entre pasado y presente, de manera que tratan el contenido histórico a partir del análisis e interpretación de los cambios y las permanencias, la explicación causal y cómo el pasado afecta al presente. Es decir, ponen acento en la necesidad de crear conciencia para entender quiénes somos, tomando de referencia el pasado como perspectiva para construir su propia identidad y comprender qué somos como individuos y como sociedad.

En referencia al perfil de docente "crítico", estos se centran en el desarrollo del pensamiento crítico y reflexivo en sus alumnos, ayudándoles a ser más conscientes de su pasado y su presente, y más activos en la construcción de un futuro mejor. Los estudiantes de profesor utilizan elementos temporales que estructuran el tiempo histórico, y desarrollan estrategias metodológicas relacionadas con el análisis e interpretación de las fuentes, la comparación y la explicación causal. Tratan el hecho histórico más allá de su conexión con el presente para que el alumnado reflexione sobre cómo puede afectar el conocimiento del pasado a las decisiones futuras. El docente crítico relaciona el contenido histórico para ayudar al alumnado a aprender a construir posibles futuros socialmente más justos y sostenibles.

En base a la descripción de las categorías que utilizamos para el análisis de la información, clasificamos el $50 \%$ de la muestra- 11 del total de las propuestas didácticas analizadas- en el perfil de docente "reproductor". En la información que presentan, los y las estudiantes tratan la enseñanza del tiempo histórico desde una perspectiva de carácter tradicional, ya que abordan los contenidos históricos partiendo del estudio del pasado, sin establecer conexiones con el presente y mucho menos con el futuro.

Los y las estudiantes del grado que se encuadran en este perfil han diseñado propuestas didácticas en las que su alumnado, de manera general, debe identificar y reconocer características generales de un período o etapa concreta de la historia y ordenarlas cronológicamente en una línea del tiempo o en un friso cronológico, presentando la información en un mural, PowerPoint o utilizando herramientas digitales.

En algunos casos, como actividad significativa, han propuesto la reconstrucción de un puzle sobre hechos relevantes de la historia, han trabajado el pasado a través del arte o han realizado una representación teatral sobre la etapa histórica estudiada.

Si bien, podemos decir que llevan a cabo metodologías en las que se fomenta la participación del alumnado, entendemos que, desde la visión que otorgan al contenido histórico, difícilmente pueden lograr que sus alumnos y alumnas lleguen a entender y manejar la complejidad del mundo en el que viven, cuyos fenómenos históricos están profundamente entrelazados con su realidad. 


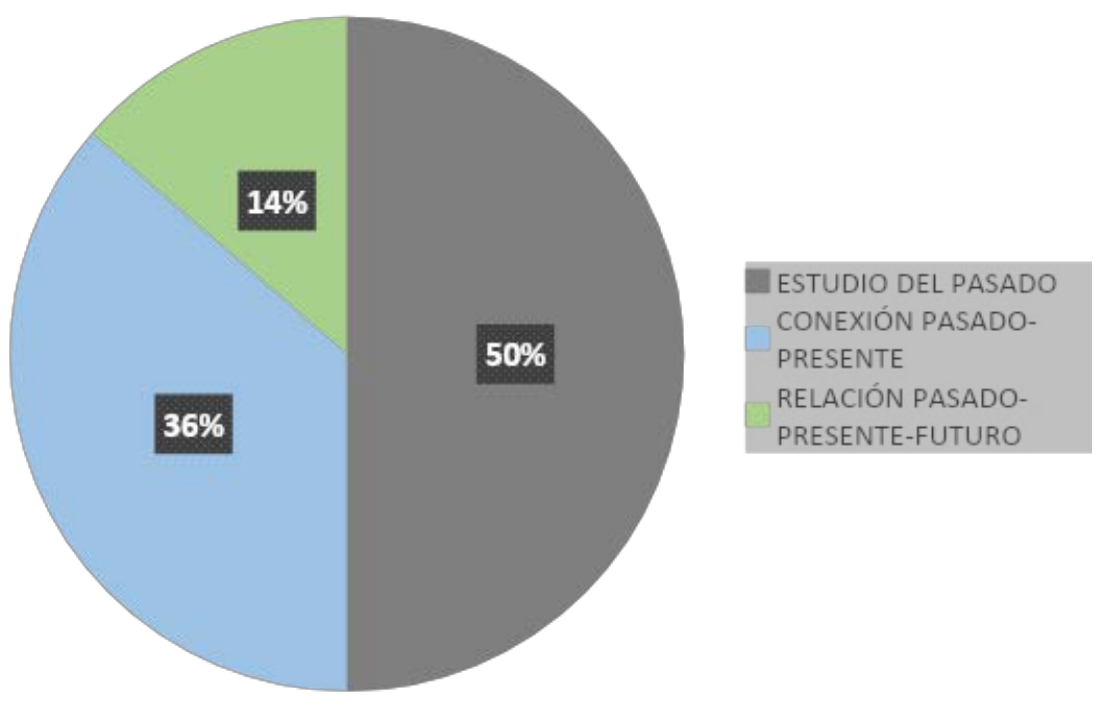

Figura 3. Clasificación de los discursos de las propuestas didácticas analizadas por categoría.

Fuente: Elaboración propia

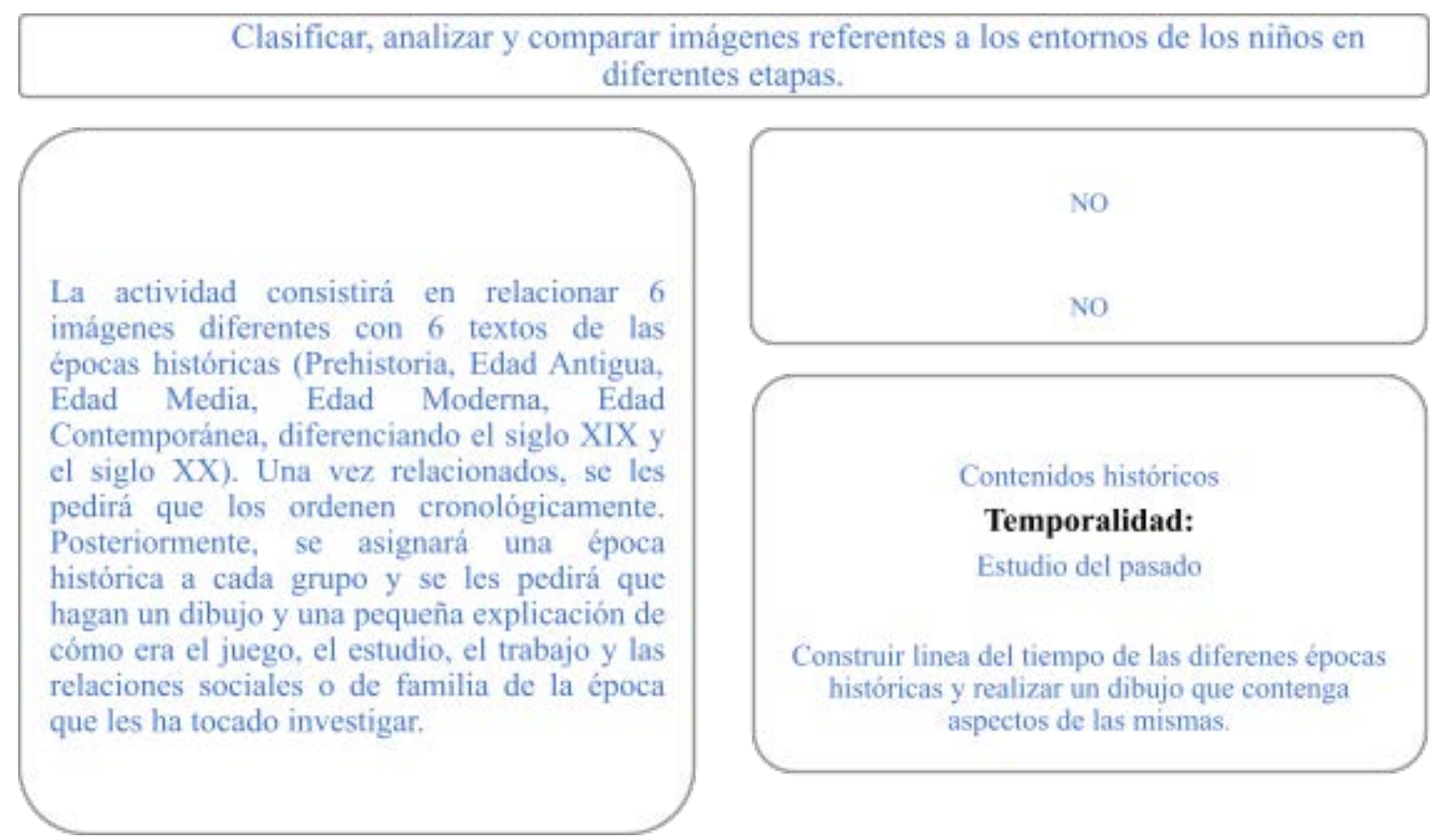

Figura 4. Información recogida de la propuesta didáctica diseñada por el estudiante Martín

\section{Fuente: Elaboración propia}

Tomamos como ejemplo dos propuestas didácticas que se enmarcan en este perfil de docente "reproductor". El estudiante Martín (Figura 4), propone como tarea que su alumnado relacione una serie de imágenes, previamente seleccionadas por él, con una época histórica concreta, y que las ordenen cronológicamente. Como se puede apreciar, en esta propuesta didáctica se trabajan conceptos temporales relacionados únicamente con la cronología y la periodización. Martín no establece conexión alguna entre fenómenos del pasado y su relación con 
el presente, y tampoco trata de que su alumnado analice e interprete los cambios y las continuidades del hecho histórico, así como su causalidad. En líneas generales, trabaja el curso de la historia desde una perspectiva narrativa, siendo difícil que este conocimiento pueda llegar a ser significativo para el alumnado si no conecta con su realidad más cercana y pueda entender que los hechos del pasado son el resultado de su presente.

La estudiante Carla se identifica también en el perfil de docente "reproductor". Propone analizar las diferentes épocas que definen la Edad Antigua y su alumnado debe investigar sobre aspectos generales de cada civilización - aspectos que no detalla en la descripción de la actividad. Asimismo, plantea la creación de un mural que, posteriormente, expondrán al grupo-clase a través de una representación teatral (Figura 5). La propuesta pone más énfasis en el aprendizaje del contenido histórico que en el aprendizaje de elementos temporales que permitan comprender el tiempo histórico en todas sus dimensiones, relacionando el contenido histórico únicamente con el pasado.

Identificar y describir los acontecimientos más relevantes de La edad Antigua.
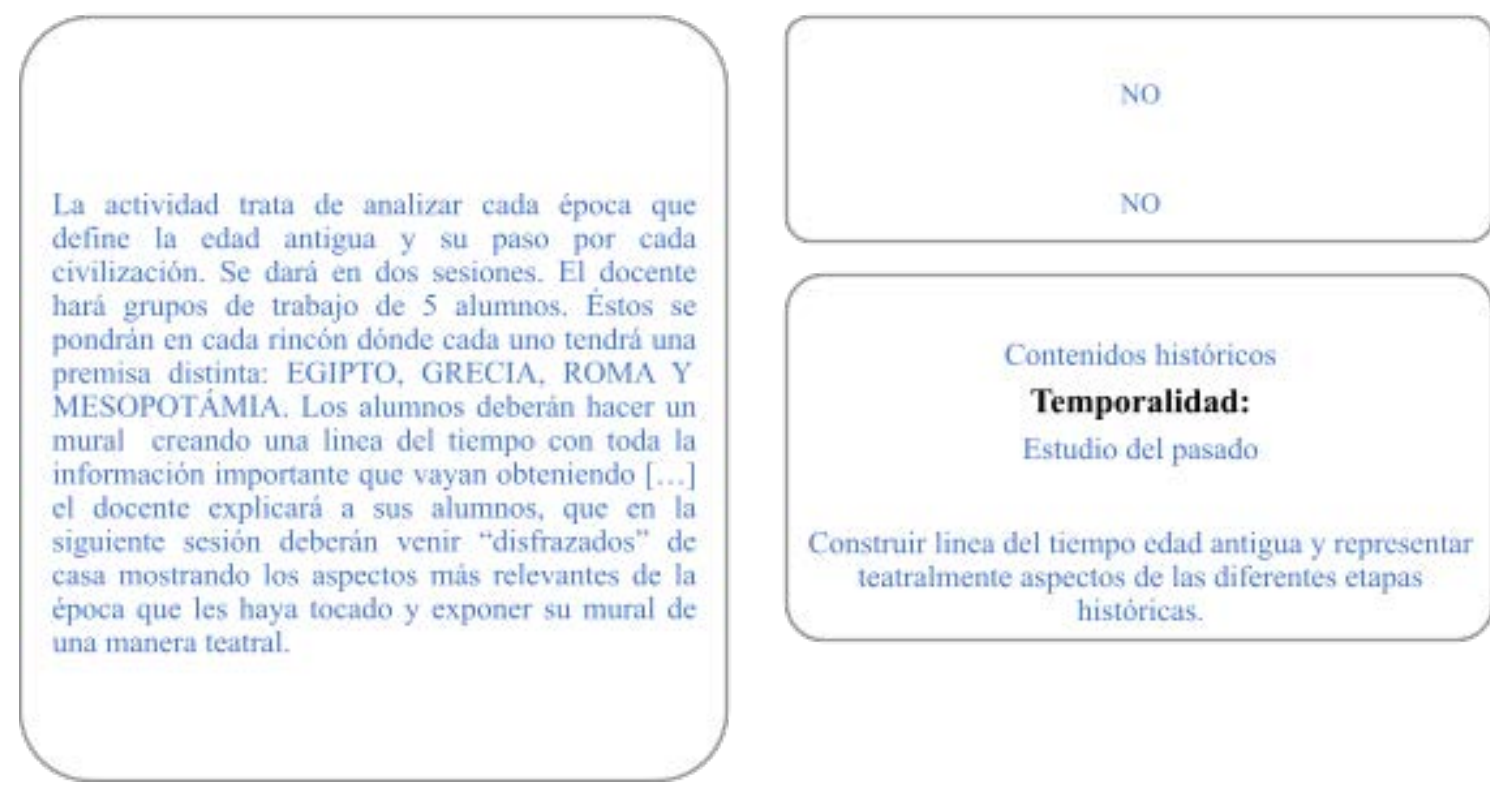

Figura 5. Información recogida de la propuesta didáctica diseñada por la estudiante Carla

\section{Fuente: Elaboración propia}

El 36\% del total de la muestra - 8 de las propuestas didácticas analizadas- describen estrategias didácticas que se vinculan al perfil de docente "humanista". En ellas identificamos algunos de los elementos temporales que forman parte del tiempo histórico como son la datación, periodización, cambio, continuidad, duración y simultaneidad, pasado y presente.

En general, las propuestas son significativas para el alumnado ya que conectan con su realidad más cercana, pues en la mayoría de ellas tratan la enseñanza del tiempo histórico partiendo de su historia personal o familiar, para así descubrir aspectos de su vida que favorece la comprensión de los cambios y las continuidades. 
Los estudiantes proponen la reconstrucción de la historia de la propia persona y de la familia a partir de fotografías, objetos y evidencias. En otras propuestas encontramos actividades que, a través de una mirada retrospectiva, conectan el conocimiento histórico con el conocimiento de su realidad presente.

Pensamos que este tipo de actividades facilita la enseñanza de elementos temporales como el cambio, la continuidad, la cronología, la simultaneidad, la sucesión, la relación entre el pasado y el presente, desde la cotidianidad y sus vivencias personales. Es entonces cuando el alumnado va formando un sentido de la temporalidad, que le permite percibir los cambios que se han operado y cambia la manera de ver la realidad. Los alumnos y alumnas se deslizan del pasado al presente y esta estrategia les ayuda a explicar el proceso histórico. Sin embargo, estas actividades no conectan con sus expectativas de futuro, no se les ofrece la posibilidad de que puedan imaginar futuros posibles.

Como ejemplo, la estudiante Sandra, parte de la idea de que la comprensión del concepto de paso del tiempo puede ayudar al alumnado a conocer el mundo en el que vive y saber a dónde quiere dirigirse en el futuro. Para ello, plantea una propuesta didáctica que parte del presente, de manera que el alumnado realizará una retrospección al pasado y construirá una línea del tiempo con aquellos acontecimientos más significativos de sus vidas. Sin embargo, a pesar de su intención por que el alumnado relacione el paso del tiempo con el futuro, este no se aborda en ninguna de las actividades propuestas. Si bien el aprendizaje es significativo y sus ideas se relacionan con el perfil de docente "crítico", Sandra se enmarca en el perfil de docente "humanista".

Realizar una introspección en los recuerdos vitales de cada alumno/a, y realizar una primera aproximación al concepto temporal del pasado.

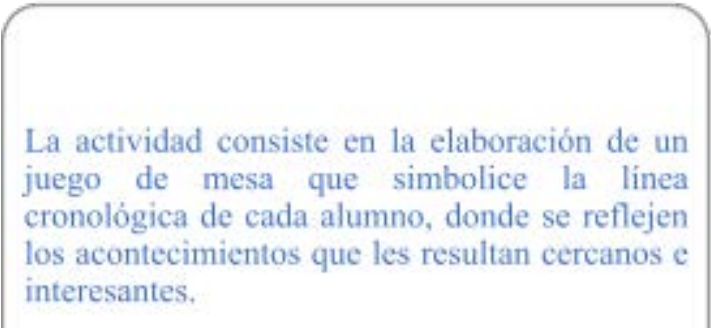
interesantes.

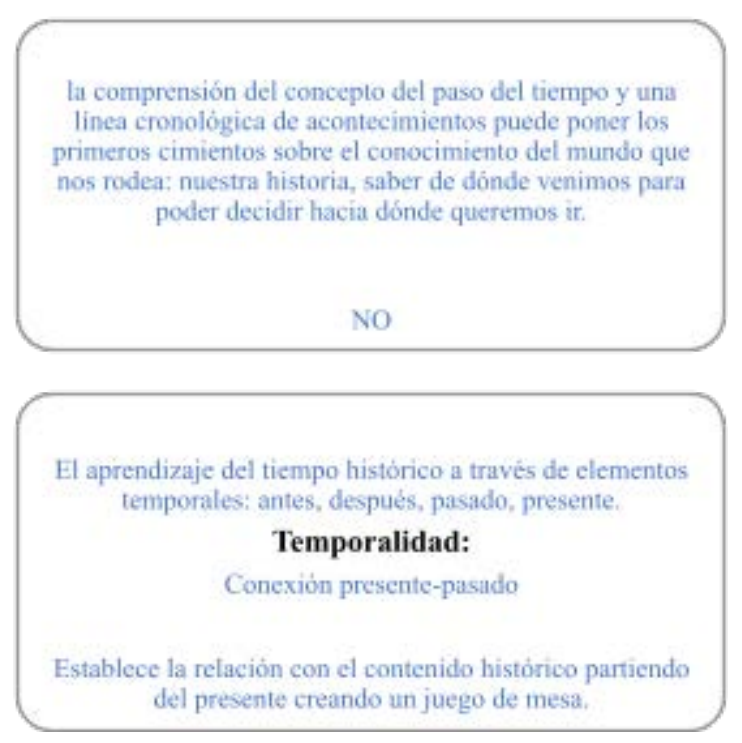

Figura 6. Información recogida de la propuesta didáctica diseñada por la estudiante Sandra

\section{Fuente: Elaboración propia}

En la misma línea, Jorge diseña una propuesta didáctica que parte del estudio del patrimonio cultural existente en la ciudad donde está ubicado el centro educativo en el que se 
llevará a cabo la actividad. Se propone la construcción de un juego de rol en el que cada alumno y alumna asume un papel y una función a llevar a cabo. La finalidad es que entiendan cómo se organizaba la sociedad en el pasado y analicen las dificultades que podrían encontrase en esa época. Si bien, esta propuesta puede ayudar a reflexionar al alumnado sobre las consecuencias del pasado en el presente y fomenta la empatía histórica, existe la posibilidad de que aparezca cierto presentismo en el momento que se le pida al alumnado que interprete los hechos del pasado y exponga las posibles dificultades que se encontrarían en esa época. De ahí la relevancia de que la historia debe ser entendida en un contexto global: geopolítico, económico, tecnológico, demográfico... y debe ser leída en clave histórica, es decir, en el pensamiento de la época y con la realidad que se vivía en esa época concreta.

Reconocer la cultura celta y conectarla con el mundo actual. Conocer a fondo la organización jerárquica, oficios, materiales y usos de recursos naturales que hacian los Celtas en los asentamientos producidos en Vigo.
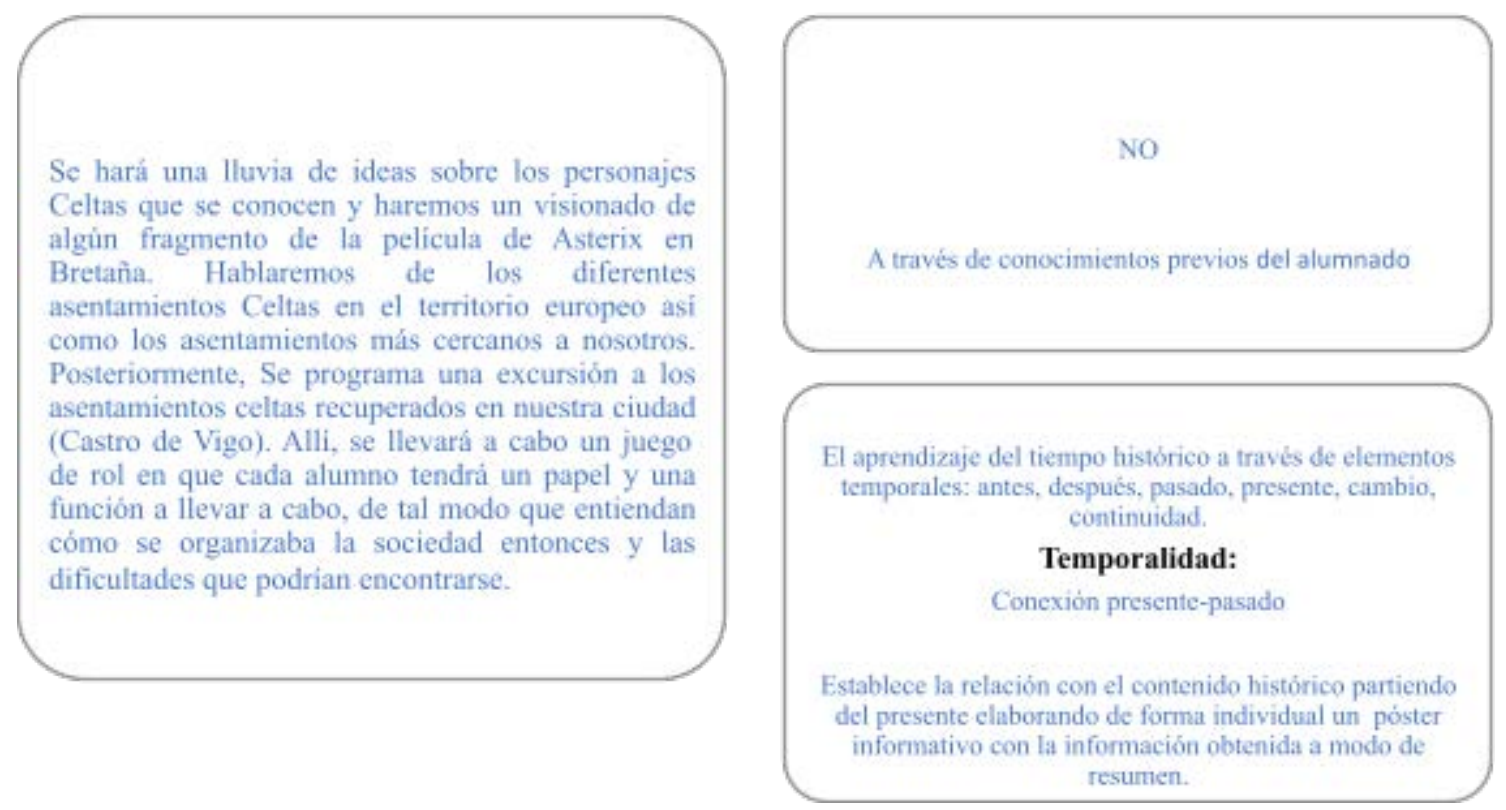

Figura 7. Información recogida de la propuesta didáctica diseñada por el estudiante Jorge

\section{Fuente: Elaboración propia}

Con un porcentaje menor, que representa el 3\% de la muestra - 3 del total de propuestas analizadas- los y las estudiantes se enmarcaron en el perfil de docente "crítico" ya que en sus actividades didácticas abordan la relación entre pasado-presente-futuro, pues han tenido en cuenta el análisis del pasado, más allá de la comprensión del presente y se proponen que su alumnado pueda pensar en el futuro a partir del conocimiento de situaciones o problemas pasados. Es el caso de la propuesta didáctica de Andrea, comienza la actividad partiendo de una noticia publicada en la prensa en la que se expone la situación de crisis económica actual y cómo en algunas organizaciones sociales se plantean recuperar el trueque como actividad económica para mitigar esta situación, de manera que se eduque al alumnado hacia el consumo responsable, fomentar la sostenibilidad y recuperar el valor de las cosas. 
Identificar en el medio físico, social y cultural cambios y transformaciones relacionadas con el paso del tiempo, reconociendo algunas relaciones de simultaneidad y sucesión para situar momentos relevantes en la historia. Tomar conciencia del valor del dinero y sus usos mediante el consumo responsable.
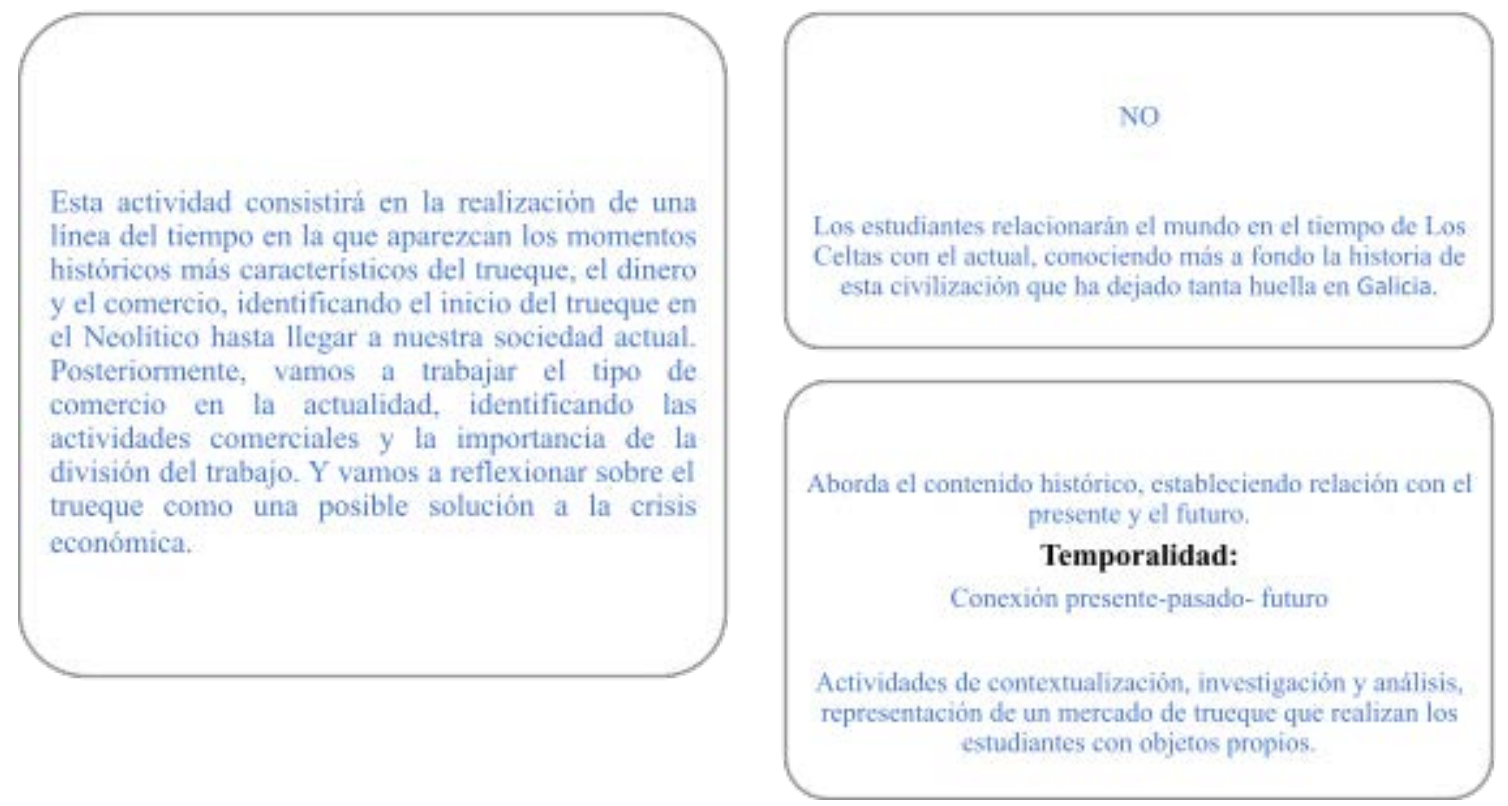

Figura 8. Información recogida de la propuesta didáctica diseñada por la estudiante Andrea

\section{Fuente: Elaboración propia}

Observar el paso del tiempo en algunos elementos del entorno próximo. Relacionar elementos del pasado, del presente y pensar en el futuro.
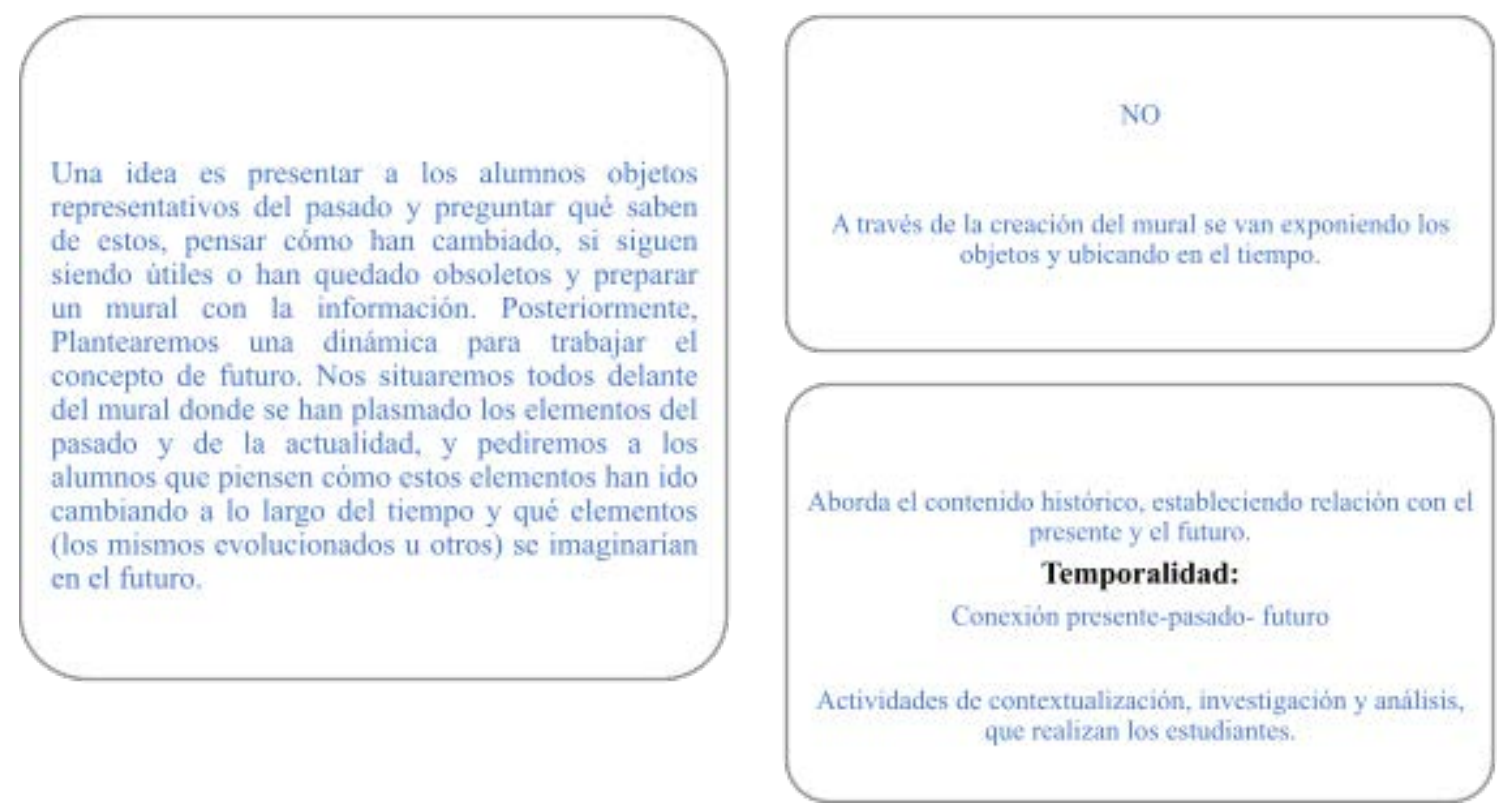

Figura 9. Información recogida de la propuesta didáctica diseñada por el estudiante Víctor Fuente: Elaboración propia 
Desde una concepción muy similar a la de Sandra, Víctor plantea una dinámica para trabajar el concepto de futuro en la enseñanza de la historia. Previamente el alumnado ha seleccionado un objeto concreto de su vida cotidiana y ha conocido el origen del mismo y su repercusión en el presente. Posteriormente, les plantea que imaginen cómo podrían evolucionar estos objetos y si estos pueden ser útiles en el futuro.

De una manera lúdica, Víctor pretende ayudar al alumnado a construir su propio conocimiento sobre la realidad y abrir las puertas a la reflexión sobre el futuro.

\section{Conclusiones}

Al inicio de este estudio nos cuestionábamos si, en la actualidad, el alumnado de primaria y secundaria logra adquirir las competencias necesarias para comprender el presente desde el análisis e interpretación del pasado y, a su vez, este conocimiento histórico les ayudase a desarrollar pensamiento crítico y conciencia de ciudadanía para pensar en la construcción del futuro; máxime si tenemos en cuenta la producción científica que se ha extendido en las últimas décadas en el campo de la didáctica de las ciencias sociales y, en concreto, de la historia.

Los resultados aquí presentados, señalan que no es así, el futuro no acaba de abordarse como una categoría temporal significativa para trabajar en la enseñanza de la historia. Si bien, las actividades analizadas muestran el interés de los y las futuras docentes de primaria por enseñar los contenidos históricos, para que su futuro alumnado comprenda el mundo en el que vive, podemos pensar que ha habido un cambio en sus ideales respecto a las finalidades de la enseñanza de la historia, pues a través de sus propuestas didácticas, manifiestan querer romper con la enseñanza de una historia tradicional y hacerla mucho más significativa para su alumnado. Sin embargo, como ya vimos en los estudios con los que iniciamos nuestra investigación (Escribano, 2019; Pagès, 1999; Santisteban, 2005) a la hora de considerar qué es lo importante de la enseñanza de la historia, ya sea por las herramientas de las que disponen, por la formación práctica que reciben o por sus inseguridades como docentes noveles, sus propuestas didácticas acaban derivando en una enseñanza de la historia que continúa privilegiando el pasado y se olvidan del ideal que han ido construyendo durante su formación en la asignatura, en relación con la utilidad que supone el aprendizaje de la historia.

Respecto a la enseñanza del tiempo histórico, los y las estudiantes continúan reproduciendo un aprendizaje de carácter lineal en el que explican los hechos históricos y los ubican en períodos o etapas históricas, incidiendo así en el aprendizaje de la temporalidad únicamente vinculada al estudio de la cronología y la periodización. Estos resultados son muy similares a los que presentaron Bravo Penjeam, Jara y Llusà (2017) en referencia a las ideas previas y el dominio conceptual del tiempo histórico por parte de estudiantes del Grado de Educación Primaria y del Grado de Historia, ya que la mayoría asocian la enseñanza del tiempo histórico con la ordenación temporal cronológica y con acontecimientos sucedidos en el pasado.

Martínez Valcárcel, Souto y Beltrán (2006) en la revisión que realizó sobre diversos estudios relacionados con las prácticas docentes en las clases de historia, presenta una síntesis de algunas de las características que continúan siendo prácticas habituales en la actualidad: uso del libro de texto, escasa utilización de metodologías para la resolución de problemas, actividades que 
fomentan más el trabajo individual que en equipo y poco compromiso del docente por la búsqueda de la racionalidad histórica, predominando la exposición narrativa cronológica.

El estudio de Bravo Penjeam (2002) presenta unos resultados similares y señala que los y las estudiantes en formación pueden ser críticos respecto a la enseñanza que han recibido en su formación académica e incluso tener una concepción mucho más renovada que la que tenían sus profesores, sin embargo, cuando llevan a cabo sus prácticas en el contexto real de un aula, acaba teniendo mucho más peso la metodología tradicional que la innovación que habían previsto en sus programaciones. Parece pues que la situación actual sigue siendo muy similar y se reafirma la idea de que las investigaciones y propuestas realizadas en el ámbito de la didáctica de la historia, siguen teniendo poca repercusión en la práctica real de enseñar el tiempo histórico.

Por otro lado, aunque nos hemos encontrado con propuestas didácticas que atienden a la conexión del presente con el pasado, desde una perspectiva significativa, sigue predominando una enseñanza de la historia en la que se pone más énfasis en el aprendizaje de contenidos históricos, que en fomentar la reflexión sobre las repercusiones del pasado en el presente y, sobre todo, en la relación del pasado con el futuro.

Prácticamente, en todas las propuestas se plantea una cierta innovación en la metodología y en el aprendizaje de elementos temporales que aparecen implícitos en la estructura conceptual del tiempo histórico, y que fue presentada previamente a los y las estudiantes del grado. Sin embargo, los resultados evidencian lo que ya se apuntaba en el marco teórico de nuestro trabajo, la enseñanza de la temporalidad aparece como la continuidad entre el ayer y el hoy, pero no entre el mañana.

Pensamos que más allá de la complejidad que supone la aprehensión de esta dialéctica entre pasado-presente y futuro, la dificultad que implica su enseñanza y aprendizaje reside, más bien, en el tipo de prácticas y estrategias docentes que aplica el profesorado, que en las propias limitaciones que puedan presentar el alumnado de primaria y secundaria durante su aprendizaje.

En este sentido, sostenemos que en la formación inicial y continua del docente debemos tomar como base las propuestas y estudios que la investigación nos ofrece, ya que todas ellas son alternativas a la linealidad temporal que plasma el estudio de la cronología.

Llevar a cabo métodos y estrategias didácticas como el método retrospectivo (Simón de Molina, 1970), la microhistoria e Historia Global (Levi, 2018; Matozzi, 2015), partir de los problemas socialmente relevantes o cuestiones socialmente vivas (Pagès, 2009; Jiménez Martínez y Felices de la Fuente, 2018), la interpretación de la contemporaneidad (Llusà, 2015), la multiculturalidad aplicada al tiempo histórico (Valls, 2011), derivan de experiencias teóricoprácticas donde se analiza críticamente la enseñanza de la historia, y en las que se plantea la necesidad de vincular el presente y el pasado, como condición fundamental para la comprensión de los procesos y las transformaciones sociales del futuro.

Por otro lado, somos conscientes de que la tarea de enseñar implica la puesta en marcha de propuestas didácticas que deben estar basadas en el currículo, pero en ellas también influye, y mucho, la visión del docente, en base a las concepciones que ha ido construyendo a lo largo de su formación inicial sobre cómo y para qué enseñar la historia y las Ciencias Sociales. Las representaciones sociales de los docentes en formación se relacionan con el significado que 
atribuyen a la enseñanza, a los contenidos que se enseñan y a la manera de hacerlo. Es decir, han ido creando sus propios modelos sobre la enseñanza partiendo de sus experiencias, ideales y creencias (Pagès, 2004; Santisteban, 2005; Escribano, 2019). En este sentido, cuestionarse por qué y para qué enseñamos la historia, qué función y utilidad tiene el conocimiento histórico, nos orienta en el camino que debemos seguir para reflexionar sobre cómo debemos desempeñar nuestra labor docente en esta área, máxime, si tenemos en cuenta el papel que los y las estudiantes desempeñarán en la sociedad.

Todo ello nos abre un panorama didáctico en el que no podemos perder de vista el carácter complejo y dinámico que tiene la enseñanza de la historia y que, como futuros docentes deberemos afrontar en nuestras aulas. Quizás la respuesta ya no sea la de ofrecer una gran cantidad de conocimientos históricos y sociales a nuestro alumnado, si no la de ayudarles a ordenar sus pensamientos, sus ideas previas, y situarles en la realidad que están viviendo para que ellos también puedan comprender la complejidad que caracteriza a nuestra sociedad.

Todos estos aspectos nos dirigen hacia unas prácticas educativas en las que se encuentren presentes modos de pensar y actuar que favorezcan la construcción del pensamiento histórico y el desarrollo de la conciencia histórica para pensar en el futuro y, por ende, desarrollar conciencia de ciudadanía democrática, participativa y crítica.

\section{Referencias bibliográficas}

Anguera, C. (2012). El concepto de futuro en la enseñanza de las Ciencias Sociales. Estudios de caso en la Educación Secundaria [Tesis Doctoral]. Universidad Autónoma de Barcelona.

Anguera, C. (2014). Per què educar per al futur? Perspectiva Escolar. 373, 34-38.

Blanco, A. (2007). La representación del tiempo histórico en los libros de texto de primero y segundo de la Enseñanza Secundaria Obligatoria. [Tesis doctoral]. Universidad de Barcelona.

Bravo Pemjean, L. (2002). La Formación Inicial del Profesorado de Secundaria en Didáctica de las Ciencias Sociales en la Universidad Autónoma de Barcelona: un estudio de caso. [Tesis Doctoral]. Universidad Autónoma de Barcelona.

Bravo Pemjean, L., Jara, M.A. y Llusà, J. (2017). La concepción del tiempo histórico en futuros docentes de Argentina, Chile y España. Pasado Abierto. Revista del CEHis. 6, 135-155.

Carretero, M. y Montanero. M. (2008). Enseñanza y Aprendizaje de la Historia: Aspectos cognitivos y culturales. Cultura y Educación. 20 (2), 133-142.

Castellvi, J.; Tosar, B. y Andreu, B. (2020). La lectura crítica de los medios digitales. Iber: Didáctica de las ciencias sociales, geografía e historia. 99, 7-14.

Escribano, C. (2019). Enseñar a enseñar el tiempo histórico. ¿qué saben y qué aprenden los futuros docentes de Secundaria? [Tesis Doctoral]. Universidad Internacional de la Rioja.

Henríquez, R. (2008). El aprendizaje de la explicación y la comprensión histórica. La construcción narrativa del pasado y la conciencia histórica de los alumnos inmigrantes en Catalunya. [Tesis doctoral]. Universidad Autónoma de Barcelona.

Jiménez Martínez, M.D y Felices de la Fuente, M. (2018). Cuestiones socialmente vivas en la formación inicial del profesorado: La infancia refugiada siria como problemática. Revista de Investigación en Didáctica de las Ciencias Sociales. 3, 87-102. 
Levi, G. (2018). Microhistoria e historia global. Historia Crítica. 69, 21-35.

Llusá, J. (2015). Ensenyar història des de la contemporaneïtat: Estudi de cas sobre la construcció $i$ aplicació del concepte contemporaneïtat a l'ESO. [Tesis Doctoral]. Universitat Autònoma de Barcelona.

Maestro, P. (2001). Conocimiento histórico, enseñanza y formación del Profesorado. En Arrondo, C. y Bembo, S. (eds.). La formación docente en el profesorado de historia. Un ámbito en conflicto. (pp. 71-113). Homo Sapiens.

Martínez Valcárcel, N., Souto, N., Beltrán, J. (2006). Los profesores de historia y la enseñanza de la historia en España. Una investigación a partir de los recuerdos de los alumnos. Revista de Enseñanza de las Ciencias Sociales. 5, 55-71.

Mattozzi, I. (2015). Una epistemología y una metodología de la Historia para la Didáctica. DiálogosRevista do Departamento de História e do Programa de Pós-Graduacâo em História. 19,(1), 57-72.

Pagès J. y Santisteban, A. (2010). La enseñanza y el aprendizaje del tiempo histórico en la Educación Primaria. Cedes. 30, (82), 281-309.

Pagès, J. (1988). Situar-se en el temps, situar-se en la historia. Guix. 124, 11-16.

Pagès, J. (1989). Aproximación a un currículum sobre el tiempo histórico. En Rodríguez Frutos, J. (ed.). Enseñar historia. Nuevas propuestas. (pp.107-138). Cuadernos de Pedagogía.

Pagès, J. (1997). El tiempo histórico. En Benejam, P. y Pagès, J. (coord.). Enseñar y aprender ciencias sociales, geografía e historia en la educación secundaria, (pp.189-208). Horsori.

Pagès, J. (1999a). El tiempo histórico: ¿Qué sabemos sobre su enseñanza y su aprendizaje? Análisis y valoración de los resultados de algunas investigaciones. AA.VV.: Aspectos didácticos de Ciencias Sociales. 13. (pp. 241-278). Zaragoza: ICE-Universidad de Zaragoza.

Pagès, J. (1999b). Es necesario conectar los contenidos históricos con los problemas del presente. Novedades Educativas. 100, 10-11

Pagès, J. (2004). Tiempos de cambios... ¿cambios de tiempos? Sugerencias para la enseñanza y el aprendizaje del tiempo histórico a inicios del siglo XXI. En Ferraz, F. (org.). Reflexôes sobre espaço-tempo. (pp. 35-53), Quarteto editora.

Pagès, J. (2007). La educación para la ciudadanía y la enseñanza de la historia: cuando el futuro es la finalidad de la enseñanza del pasado. En Ávila, R. et.al. (eds). Las competencias profesionales para la enseñanza-aprendizaje de las Ciencias Sociales (pp. 205-215). Asociación Universitaria del Profesorado de Didáctica de las Ciencias Sociales.

Pagès, J. (2009). Consciència i temps històric. Perspectiva escolar, (332), 2-8.

Pagès, J. (2011). Enseñar historia, enseñar a construir el futuro. ¿Qué nos enseña la historia acerca de cómo intervenir en la construcción del futuro? International Standing Conference for the History of Education, ISCHE 33. Estado, educación y sociedad. Nuevas perspectivas para un viejo debate. San Luis Potosí, México

Pagès, J. (2019). Enseñar historia, educar la temporalidad, formar para el futuro. El futuro del pasado. 10, 19-56. 
Pagès, J. y Santisteban, A. (1999). La enseñanza del tiempo histórico: una propuesta para superar viejos problemas. En Teresa García Santa María (Coord.). Un currículum de Ciencias Sociales para el siglo XXI. Qué contenidos, para qué. (pp. 187-207). Díada editora.

Pagès, J. y Santisteban, A. (2008). Cambios y continuidades: aprender la temporalidad histórica. En Jara, M.A. (coord.). Enseñanza de la Historia. Debates y Propuestas (pp. 91-127). Editorial de la Universidad Nacional del Comahue.

Pons, M. (2007). Canvi i continuïtat : conceptes clau en l'ensenyament de les ciències socials en l'educació secundària obligatòria [Tesi doctoral]. Universitat Autònoma de Barcelona.

Sandín, M.P. (2003). La enseñanza de la investigación cualitativa. Revista de Enseñanza Universitaria. 21, 37-52.

Santisteban, A. (2005). Les representacions i l'ensenyament del temps històric Estudis de cas en formació inicial de mestres de primària en Didàctica de les Ciències Socials. [Tesis Doctoral]. Universitat Autònoma de Barcelona.

Santisteban, A. (2007). Una investigación sobre cómo se aprende a enseñar el tiempo histórico. Enseñanza de las ciencias sociales: Revista de Investigación. 6, 19-30.

Santisteban, A. y Anguera, C. (2014). Formación de la conciencia histórica y educación para el futuro. Clío y asociados. 18-19, 249-267.

Santisteban, A., González, N., Pagés, J. (2010). Una investigación sobre la formación del pensamiento histórico. En Ávila Ruiz, P.; Rivero, M.P. y Domínguez Sanz, P. (coords.). Metodología en investigación en Didáctica de las Ciencias Sociales, (pp. 115-128). Instituto Fernando el Católico.

Seixas, P. y Morton, T. (2013). The big six historical thinking concepts. Nelson Education.

Simón de Molinas, S. (1970). El método retrospectivo en la enseñanza de la historia. Estrada.

Torres, P. A. (2001). Enseñanza del tiempo histórico. Historia, Kairós y Cronos. Una unidad didáctica para el aula de ESO. Ediciones la Torre.

Tosar, B. (2018). Literacidad crítica y enseñanza de las Ciencias Sociales en primaria: Profe, las bolsas de plástico no son medusas. Revista de Investigación en Didáctica de las Ciencias Sociales. 2, 4-19.

Valls, R. (2011). La multiculturalidad en la enseñanza de la historia y el desajuste entre intenciones educativas y prácticas escolares: los retos del presente y del futuro inmediato. Educar em Revista. 42, 73-94. 